
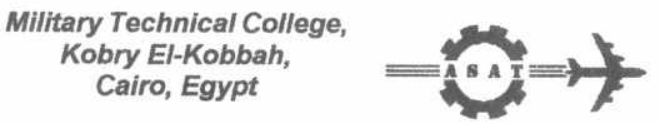

$9^{\text {th }}$ International Conference

On Aerospace Sciences \&

Aviation Technology

\title{
EFFECT OF PAYLOAD PARAMETERS ON THE DYNAMIC PERFORMANCE OF HEAVY VEHICLES
}

HOSAM EL-DEEN*Y.H., EL-HADDAD**M.A. AND SHARAF***A.M.

ABSTRACT

Nowadays the articulated heavy vehicles play an economically important role in the transportation process, and their numbers have been increasing for several decades. In the military field, the demand of transporting combat equipment that are characterized by unconventional weights and dimensions, necessitates using unconventional transporters. The payload parameters effect on the dynamic performance of heavy articulated vehicles is of a prime of interest.

In this paper parametric study is carried out to investigate the effect of payload parameters (density, and C.G height) during different low and high-speed maneuvers using yaw/roll model, which is developed by the University of Michigan Transportation Research Institute, UMTRI.

The study shows that there may exist two loading cases that having equal payload weight but with different densities and accordingly different C.G. heights. In the case of higher C.G., the dynamic rollover stability and yaw stability are reduced. Accordingly regulation laws must limit the C.G. height as with the limitation on axle loads, (i.e. axle load only is not enough limit).

\section{KEY WORDS:}

Articulated vehicle, tractor-semitrailer, and vehicle dynamic simulation.

*Professor, Higher Technological Institute, Tenth of Ramadan City, EGYPT.

** Associate Professor, Egyptian Armed Forces.

Teacher assistant, Egyptian Armed Forces. 


\section{INTRODUCTION}

This paper presents the results of the effect of payload main parameters (density, and height) during different low and high-speed maneuvers. The payload is assumed to be a rectangular shape of uniformly distributed solid material. The payload parameters are length, width, height and material density. All these parameters determine the payload weight. However the semitrailer dimensions restrict the payload width and length, so the change in payload weight is carried out either by changing density or by height.

The model used for this study is the mathematical yaw/roll model, which is developed by the University of Michigan Transportation Research Institute, UMTRI, [1], [2], [3]. The model and its computer program is developed for the purpose of describing the vehicle dynamics in the yaw and roll plane during different low and high speed maneuvers. The different performance measures used for evaluating the dynamic performance of heavy vehicle are given in references $[4,5,6,7 \& 8]$ and will be highlighted briefly.

\section{COMPUTER SIMULATION MODEL}

The "UMTRI" Yaw/roll model was developed for the purpose of predicting the directional and roll response of single and multiple-articulated vehicles engaged in steering maneuvers, which approach the rollover conditions. It should be noted that the model does not permit the simulation of braking maneuvers. The model is unique in the sense that it permits the analysis of unconventional vehicle layouts. The equations of motion are developed in such a fashion that it is possible to use the model for simulating the vehicles with:

1. Any number of placement of wheels and tires.

2. Any number of units and articulation points.

3. Any of the particular hitch mechanisms and constraints that are used in heavyduty commercial vehicles.

The computer code permits the simulation of vehicles with up to three articulation points (i.e. four sprung masses) and 11 axles. The computer program can be easily expanded to permit the analysis of vehicles with an even larger number of articulation points and axles.

In the model, the forward velocity of the lead unit is assumed to remain constant during the maneuver. Hence, each sprung mass is treated as a rigid body with five degrees of freedom: lateral, vertical, yaw, roll, and pitch. The axles are treated as beam axles, which are free to roll and bounce with respect to sprung mass to which they are attached. In its present form, the computer program permits the analysis of vehicles, which are equipped with any of four coupling mechanisms. It should be noted that the "fifth-wheel" and the "inverted fifth-wheel" permit the lead and the trailing units to yaw and pitch with respect to one another but are stiff in roll. On the other hand, the so called "king pin" connection permits only yaw motions between the lead and the trailing units. In the case of the "pintle hook", the trailing unit can roll, bounce, yaw, and pitch with respect to the lead unit. 
1. An only steering maneuver (in which the input is an angular displacement of the front wheels on the lead unit) is of interest.

2. Vehicle moves over a horizontal surface possessing uniform frictional characteristics.

3. The pitch motions of the sprung masses are small such that $\sin \theta_{\mathrm{s}}=\theta_{\mathrm{s}}, \cos \theta_{\mathrm{s}}=1$

4. The relative roll displacements between the sprung mass and the axles remain small, such that: $\sin \left(\phi_{s}-\phi_{\mathrm{u}}\right)=\left(\phi_{\mathrm{s}}-\phi_{\mathrm{u}}\right), \cos \left(\phi_{\mathrm{s}}-\phi_{\mathrm{u}}\right)=1$

5. The relative roll motion between unsprung masses and sprung masses takes place about roll centers, $\mathrm{R}$, which are located at fixed distances beneath sprung masses, Fig.1.

6. The line of action of the suspension springs remains parallel to the $\vec{k} v$ axis, with only compression and tensile forces being transmitted to the sprung mass. Fig. 1 . shows that the roll center, $\mathrm{R}$, is free to move in the $\vec{k} v$ direction, such that any force on the axle in the $\vec{J}_{u}$ direction acts on the sprung mass at the roll center, $R$. In the case of a suspension consisting of leaf springs the spring are twisted (about a longitudinal axis) when the axle rolls relative to the sprung mass, with the resulting roll resisting moment being treated as an auxiliary roll stiffness, KRS, Fig. 1

7. Non linearity's in the force-displacement behavior of a suspension such as lash are approximated as shown in Fig.2.

8. The forces acting on each axle are independent of the forces acting on adjacent axles, i.e. inter-axle load transfers are neglected.

9. The cornering force and aligning moment produced by a given tire is a nonlinear function depending only on slip angle and vertical load. The influence of wheel inclination (or camber) on lateral force generation has been neglected on the grounds that inclination angles remain small prior to wheels being lifted off the ground in a sever directional maneuver.

10. The principal axes of inertia of the sprung and unsprung masses coincide with the respective body-fixed coordinate systems.

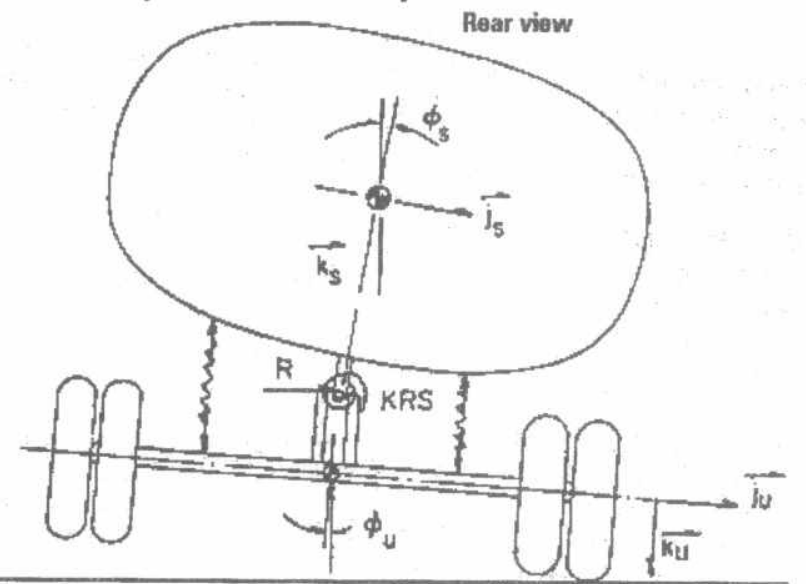

Fig.1. Idealized representation of axles and suspension springs 


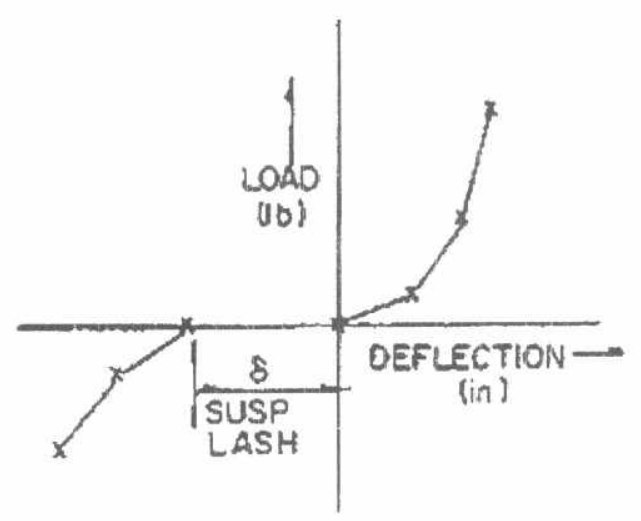

Fig.2. Idealized representation of suspension spring.

\section{PERFORMANCE MEASURES}

The performance measures used in this study are listed below, [5], [6], [7]\& [8]:

1. Dynamic load transfer ratio (LTR): The LTR is defined as the ratio of the absolute value of the difference between the sum of right wheels loads, $F_{R}$, and the sum of left wheels loads, $F_{L}$, to the sum of all wheel loads. It is calculated using open loop rapid steering lane change maneuvers.

$$
L T R=\sum\left(F_{L}-F_{R}\right) / \sum\left(F_{L}+F_{R}\right)
$$

2. Rearward amplification ratio (RWA): The RWA is defined as the ratio of the peak value (positive or negative) of lateral acceleration achieved at the mass center of the rearmost trailer to that developed at the mass center of the tractor. It is calculated using open loop rapid steering lane change maneuvers.

3. Friction demands: Friction demand is the absolute value of the ratio of the resultant shear force, $F_{Y}$, arising simply due to curvilinear travel divided by the cosine of the tractor trailer articulation angle, $\cos \Gamma$, to the vertical load imposed on those tires, $F_{Z}$.

$$
\mu=\left|\left(\sum F_{y} / \cos \Gamma\right) / \sum F_{z}\right|
$$

The friction demands can be:

a) Low speed friction demands (LFD): Which is calculated using low speed tight steering maneuver.

b) High-speed friction demand (HFD): Which is calculated using open loop rapid steering lane change maneuver.

4. Handling performance: Handling performance is a good measure that used for the evaluation of both controllability and stability of a given combination. It is calculated using ramp steer rate of $0.02 \mathrm{deg} / \mathrm{sec}$ at the front axle (NRC, National Research Council, method), and this helps to construct the three point handling diagram from which the handling characteristics can be evaluated, Fig. 3. 
The diagram is constructed using the coordinate system $\left\{\left(\mathrm{L} . \mathrm{r} / \mathrm{U}-\delta_{\mathrm{FW}}\right), \mathrm{A}_{y}\right\}$, where $\delta_{\mathrm{FW}}$ is the front wheel steer angle needed for a simple 2-axle truck of wheelbase, L, to negotiate a turn of radius, $R$, at constant vehicle speed, $U$, with yaw rate, $r$. This form of handling diagram represents the vehicle handling performance exclusive of steering system compliance. Referring to Fig. 3 the characteristics points $(A, B$ and $C)$ are considered. The three-point measure can be described as follow:

First point, (A): This point addresses the level of lateral acceleration at which the vehicle transforms from understeer to oversteer. The lateral acceleration at which the transition takes place should not be less than $.18 \mathrm{~g}$, to ensure that a reasonable level of lateral acceleration can be reached before the onsets of oversteer. This provision is aimed at ensuring that the vehicle behavior remains reasonably constant over the range of normal driving conditions of the vehicle.

Second point $(B)$ : This point addressees the understeer coefficient, $K_{\mathrm{u}}$ at a lateral acceleration of $0.3 \mathrm{~g}$. The coefficient is to be higher than the critical understeer coefficient, $K_{u c r}$, by a certain margin of safety, to prevent the driver from suffering a total loss of directional stability without warning from even a slight external perturbation. The critical understeer coefficient is defined as $\left(-\mathrm{Lg} / \mathrm{U}^{2}\right)$.

Third point $(\mathrm{C})$ : This point is designed to place upper and lower limits on the understeer coefficient $\mathrm{K}_{\mathrm{u}}$, at a lateral acceleration level of $0.15 \mathrm{~g}$, in order to ensure reasonable controllability of a heavy truck in the lower reaches of lateral acceleration. Without such limits, the driver either will have great difficulty steering the vehicle or will have trouble coping with its sensitivity. The understeer coefficient is held within a range from 0.0 to $2.0 \mathrm{deg} / \mathrm{g}$ (steerability boundary)

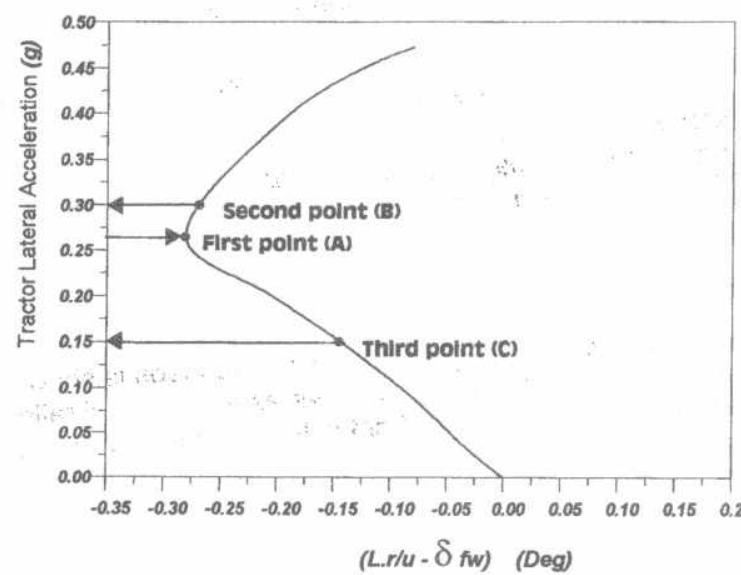

Fig.3. Representation of the three point (NRC) handling diagram measure

5. Offtracking performance: Offtracking is defined as the lateral offset of the path taken by the trailing axles of a vehicle combination from the path taken by the tractor's steering axle in a steady turn. 
a) Low speed steady-state offtracking.

Is calculated at radius $45 \mathrm{ft}(13.7 \mathrm{~m})$ measured at the center of the front steer axle. The threshold value is $(6 \mathrm{~m})$

b) Low-speed transient offtracking.

Is calculated at radius $45 \mathrm{ft}(13.7 \mathrm{~m})$ measured at the center of the front steer axle. The threshold value is $(6 \mathrm{~m})$

c) High speed steady-state offtracking.

Is calculated at speed $100 \mathrm{~km} / \mathrm{hr}$ and radius $1290 \mathrm{ft}(393 \mathrm{~m})$ measured at the center of the front steer axle. The threshold value is $(0.46 \mathrm{~m})$ to achieve the condition in which a minimal clearance of $0.15 \mathrm{~m}$ remains between the trailer tires and the outside of $3.66 \mathrm{~m}$ wide conventional traffic lane, with a $2.44 \mathrm{~m}$ wide tractor following a path down the centerline of the lane.

The baseline data of the tractor-semitrailer used in this study are provided from a published technical report, [9].

\section{EFFECT OF PAYLOAD PARAMETERS}

By assuming the payload to be a rectangular uniformly distributed solid material, the payload parameters are length, width, height and material density. All these parameters determine the payload weight. However the semitrailer length and width restrict payload corresponding dimensions, so the change in payload weight is carried out either by changing density or by height, as shown from equations 3,4 .

$$
m_{p}=\rho \times V
$$

Where $m_{p}$ is the payload weight, $\rho$ is the payload density and $V$ is the payload volume given by:

$$
V=L \times b \times h
$$

Where L, b, h are the payload length, width, and height, respectively.

\subsection{Effect of payload parameters on other design parameters}

When changing the payload weight either by changing the density or C.G height other design parameters are changed namely:

1. Tractor-semitrailer axle loads.

2. Location of total semitrailer payload center of gravity.

3. Total semitrailer payload moments of inertia.

\section{(1) Tractor-semitrailer axle loads}

The effect of payload weight on the tractor-semitrailer axle loads is shown in Fig. (4). As the payload weight increases both the tractor rear axles and semitrailer rear axles are significantly increased, while the tractor front axle is slightly increased. 


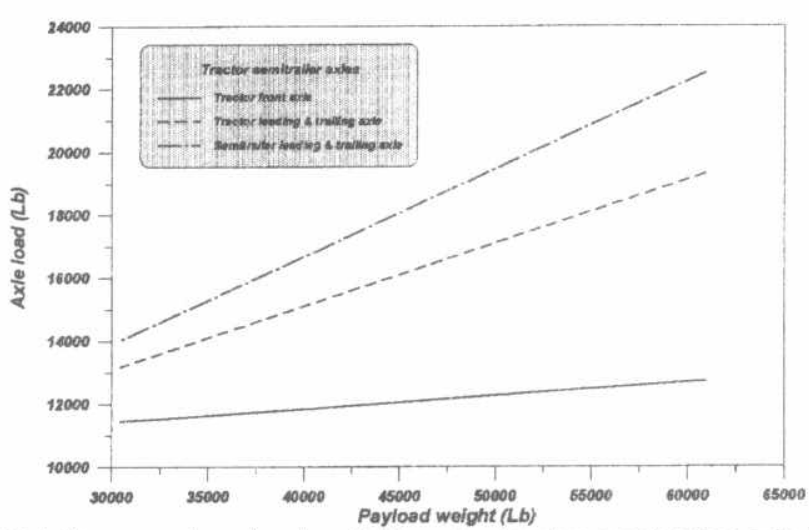

Fig. (4) Influence of payload weight on the tractor-semitrailer axle loads

\section{(2) Location of semitrailer-payload total sprung mass C.G. height}

The effect of payload weight on the total combined semitrailer-payload C.G. height is shown in Fig. (5). For the change in payload density total combined C.G. height remains constant, assuming uniform shape of payload, while for increasing payload C.G. height the total combined C.G. height is increased, equation 5.:

$$
h_{c}=\frac{\left(W_{s} \times h_{s}+W_{P} \times h_{P}\right)}{\left(W_{s}+W_{P}\right)}
$$

where: $h_{c}$ Total combined semitrailer-payload C.G. height.

$h_{s}$ Empty semitrailer C.G. height.

$h_{p}$ Payload C.G. height.

$W_{\mathrm{s}}$ Empty semitrailer weight.

$W_{p}$ Payload weight.

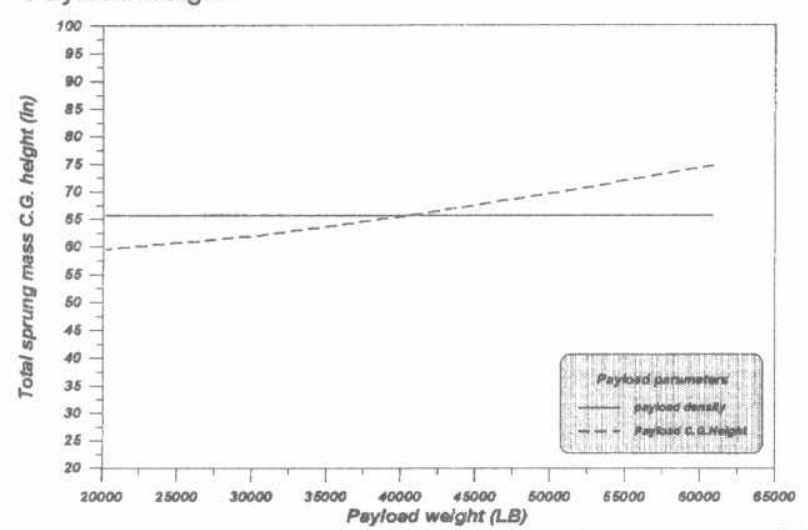

Fig. (5) Influence of payload parameters on the total sprung mass C.G.height 
The effect of payload weight on the total longitudinal center of gravity location is slightly changed and can be neglected.

\section{(3) Semitrailer-payload total sprung mass moments of inertia}

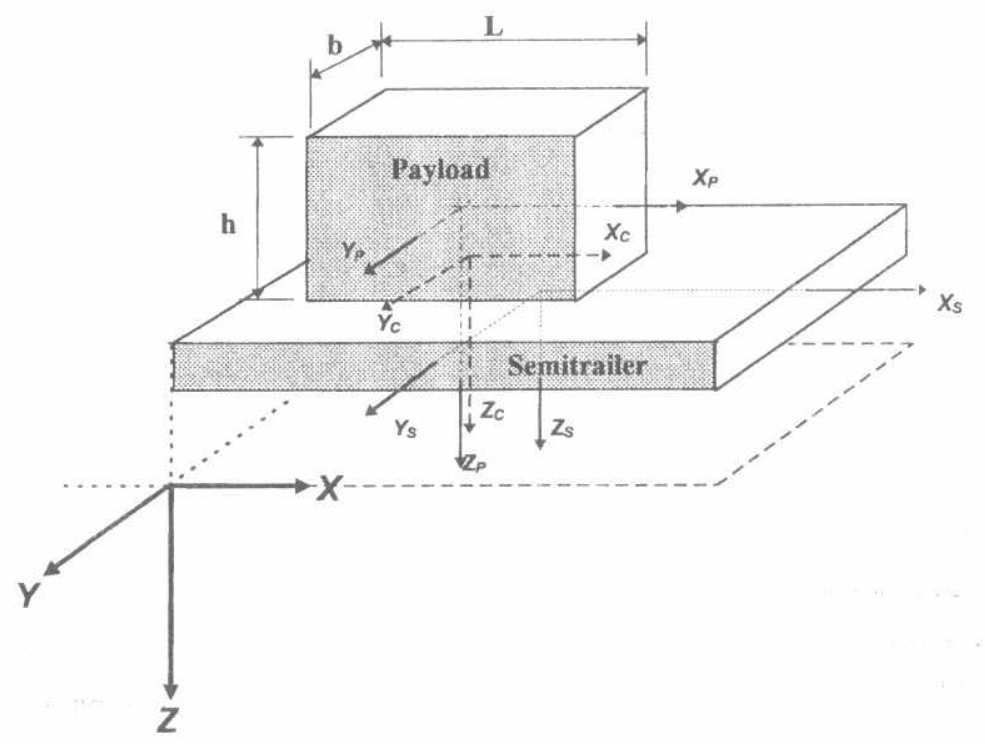

Fig. (6) Combined semitrailer- payload sprung mass

\section{Payload moments of inertia}

Payload moments of inertia can be estimated using standard formula [14]. For uniformly dense, rectangular solid shape as shown in Fig. (6). Payload moments of inertia about the axes $x_{p}, y_{p}, z_{p}$ passing through the payload center of gravity are given as follow:

$$
\left.\begin{array}{l}
I_{x x p}=\frac{m_{p}}{12} \times\left(b^{2}+h^{2}\right) \\
I_{y y p}=\frac{m_{p}}{12} \times\left(l^{2}+h^{2}\right) \\
I_{z x p}=\frac{m_{p}}{12} \times\left(b^{2}+l^{2}\right)
\end{array}\right)
$$

where

Ixxp. Payload roll moment of inertia.

lyyp. Payload Pitch moment of inertia

Izzp. Payload yaw moment of inertia. 


\section{Empty Semitrailer moment of inertia:}

The roll, pitch, and yaw moment of inertia of empty semitrailer lxxs, lyys, Izzs about the axes XS, YS, ZS passing through the empty semitrailer sprung mass center of gravity are given by [15]:

$$
\begin{gathered}
I_{x x}=1188.26 L s+22888.8 \\
I_{y y}=I_{x x}=525.889 L s^{2}-10870.2 L s+310123
\end{gathered}
$$

where: $L_{s}$ is the empty semitrailer length.

\section{Total sprung mass moment of inertia:}

The total roll, pitch, and yaw moment of inertia of the combined semitrailer and payload Ixxc, lyyc, Izzc about the axes xc, yc, zc passing through the combined sprung mass center of gravity are given as follow:

$$
\left.\begin{array}{l}
I_{x x c}=I_{x x p}+m_{p}\left\{\left(y_{p}-y_{c}\right)^{2}+\left(z_{p}-z_{c}\right)^{2}\right\}+I_{x x s}+m_{s} \times\left\{\left(y_{s}-y_{c}\right)^{2}+\left(z_{s}-z_{c}\right)^{2}\right\} \\
I_{y y c}=I_{y y p}+m_{p}\left\{\left(x_{p}-x_{c}\right)^{2}+\left(z_{p}-z_{c}\right)^{2}\right\}+I_{y y s}+m_{s} \times\left\{\left(x_{s}-x_{c}\right)^{2}+\left(z_{s}-z_{c}\right)^{2}\right\} \\
I_{z z c}=I_{z z p}+m_{p}\left\{\left(x_{p}-x_{c}\right)^{2}+\left(y_{p}-y_{c}\right)^{2}\right\}+I_{z z s}+m_{s} \times\left\{\left(x_{s}-x_{c}\right)^{2}+\left(y_{s}-y_{c}\right)^{2}\right\}
\end{array}\right\}
$$

The effect of payload weight on the combined roll, pitch and yaw moment of inertia are shown in figures (7), (8), and (9). As the payload weight increases, the total combined roll, pitch, and yaw moment of inertia increase also. The difference between the effect of payload density and payload C.G. height appears only in case of roll moment of inertia, where the effect of payload C.G. height increase gives higher roll moment of inertia which is expected to have less dynamic stability.

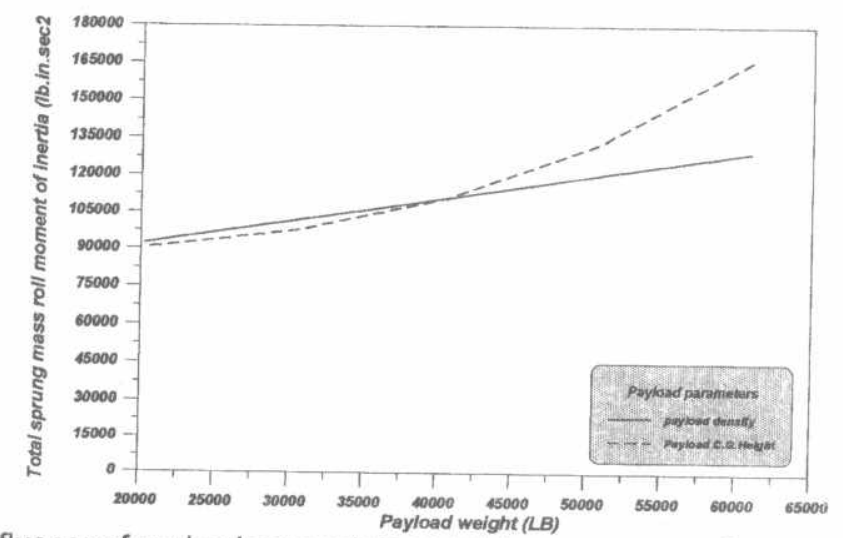

Fig. (7) Influence of payload parameters on total sprung mass roll moment of inertia. 


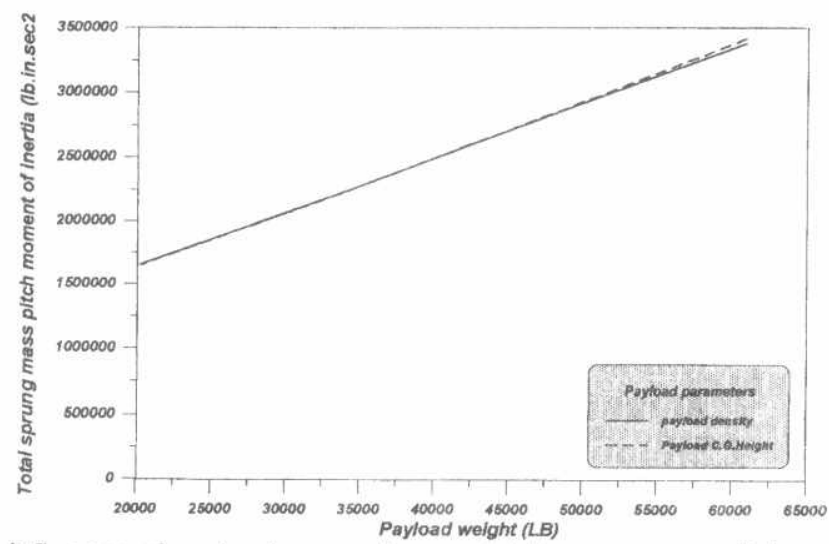

Fig. (8) Influence of payload parameters on total sprung mass pitch moment of

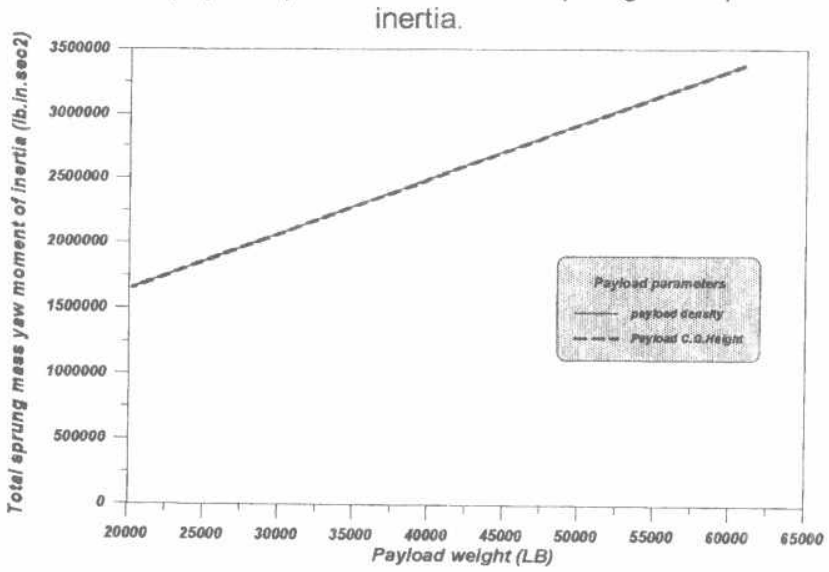

Fig. (9) Influence of payload parameters on total sprung mass yaw moment of inertia

\subsection{Effect of payload parameters on performance measures}

Available baseline data are considered as input to the Yaw/Roll model [1]. The payload is then changed either by changing payload or C.G height. The effect of this change on other design parameters is considered, as explained in section 4.1. The results of simulation show the effect on performance measures as follow:

\section{(1) Dynamic load transfer ratio}

The dynamic load transfer ratio as a function of the payload main design parameters during rapid steering lane change maneuver is shown in Fig. (10). Generally, as the payload weight increases the dynamic load transfer ratio (LTR) will increase also. 
Effect of payload density. As the payload density changes from $-50 \%(595 \mathrm{Kg} / \mathrm{m} 3)$ to $+50 \%(1785 \mathrm{Kg} / \mathrm{m} 3)$ around the baseline value $(1190 \mathrm{Kg} / \mathrm{m} 3)$ it causes a very slight change in LTR which doesn't exceed $5.5 \%$, this means that payload material or density has a small effect on LTR.

Effect of payload C.G. height: As the payload C.G. height increases from $-50 \%$ $(1.345 \mathrm{~m})$ to $+50 \%(1.932 \mathrm{~m})$ around the baseline value $(1.6383 \mathrm{~m})$ it causes an increase in LTR from $-11 \%(0.36138)$ to $+15.5 \%(0.46898)$ around the baseline value $(0.406045)$. So increasing payload C.G. height has a significant effect on the dynamic rollover stability causing it to be reduced.

From the figure, it is clear that, although the payload weight is the same, the rollover stability is reduced in case of higher center of gravity height.

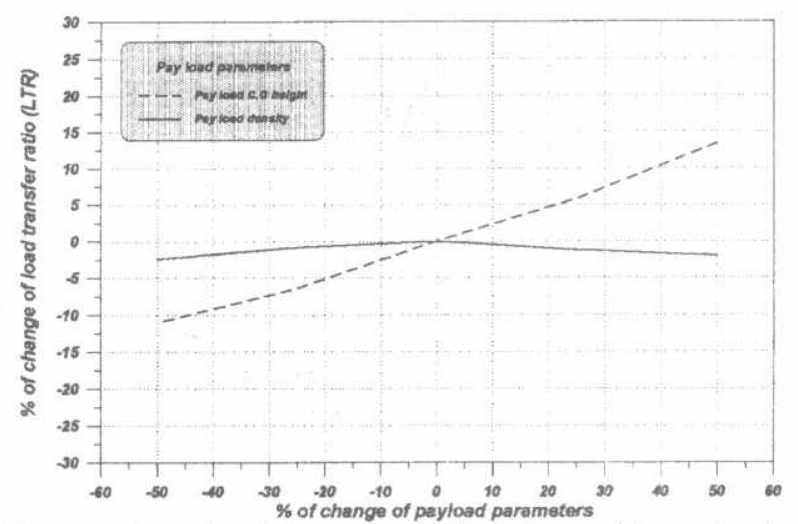

Fig. (10) Influence of payload change on LTR during rapid steering lane change maneuver (at $90 \mathrm{~km} / \mathrm{hr}$ )

\section{(2) Rearward amplification ratio}

The effect of the payload main design parameters on the rearward amplification ratio during steering lane change maneuver is shown in Fig. (11). Generally as the payload weight increases from $-50 \%(9208 \mathrm{Kg})$ to $+50 \%(27624 \mathrm{Kg})$ around the baseline value $(18416 \mathrm{Kg}$ ) the reanward amplification ratio, (RWA), decreases within slight range from $+5.5 \%(0.7826)$ to $-4.8 \%(0.7062)$ around the baseline value (0.7418).

There is no significant difference between the change in payload weight either by changing density or by C.G. height. In another word there is a slight effect of payload C.G. height on RWA 


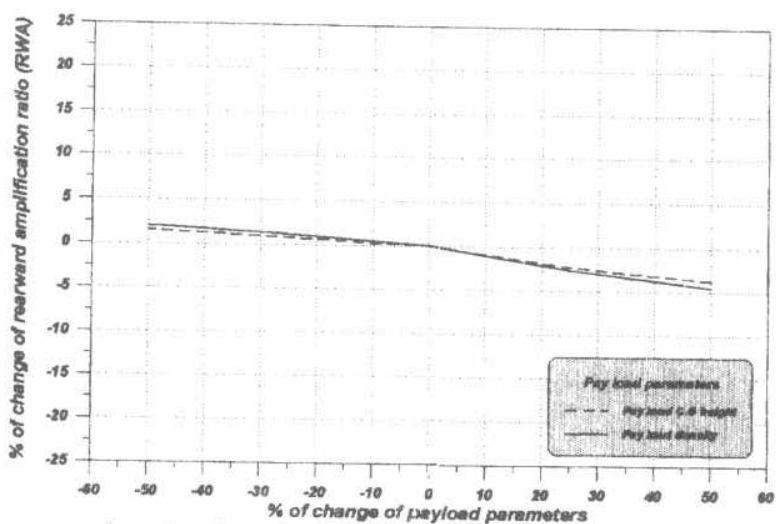

Fig. (11) Influence of payload on RWA during rapid steering lane change maneuver (at $90 \mathrm{~km} / \mathrm{hr}$ )

\section{(3) Low speed friction demand}

The effect of the payload main design parameters on the Low speed friction demand during low speed steering maneuver is shown in Fig. (12). Generally as the payioad weight increases from $-50 \%(9208 \mathrm{Kg})$ to $+50 \%(27624 \mathrm{Kg})$ around the baseline value $(18416 \mathrm{Kg}$ ), the low speed friction demand (LFD) decreases within range from $+6.5 \%(0.0609)$ to $-7 \%(0.0532)$ around the baseline value $(0.5716)$, i.e. low speed friction demand is improved by increasing payload weight. And this is mainly due to the increase in the gross vehicle weight, which increases the axle loads. There is no significant difference between the change in payload weight either by changing density or by C.G. height. I.e. there is a slight effect of payload C.G. height on LFD except at higher C.G. there is a very slight change about $1.5 \%$.

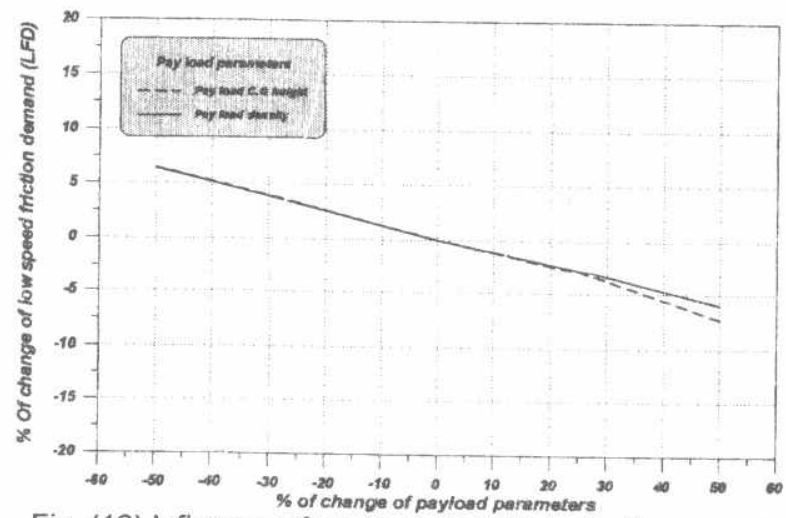

Fig. (12) Influrence of payload on LFD during low speed steering maneuver (at $5 \mathrm{~km} / \mathrm{hr}$ ) 


\section{(4) High speed friction demand}

The effect of the payload main design parameters on the high-speed friction demand during high-speed steering lane change maneuver is shown in Fig. (13). As the payload weight increases from $-50 \%(9208 \mathrm{Kg})$ to $+50 \%(27624 \mathrm{Kg})$ around the baseline value $(18416 \mathrm{Kg})$, the high speed friction demand (HFD) decreases within range from $+7.5 \%(0.2766)$ to $-10 \%(0.2316)$ around the baseline value $(0.257318)$, i.e. high-speed friction demand is improved by increasing payload weight. There is no significant difference between the change in payload weight either by changing density or by C.G. height. Hence, there is a slight effect of payload C.G. height on HFD except at higher C.G. there is a very slight change about $1.5 \%$.

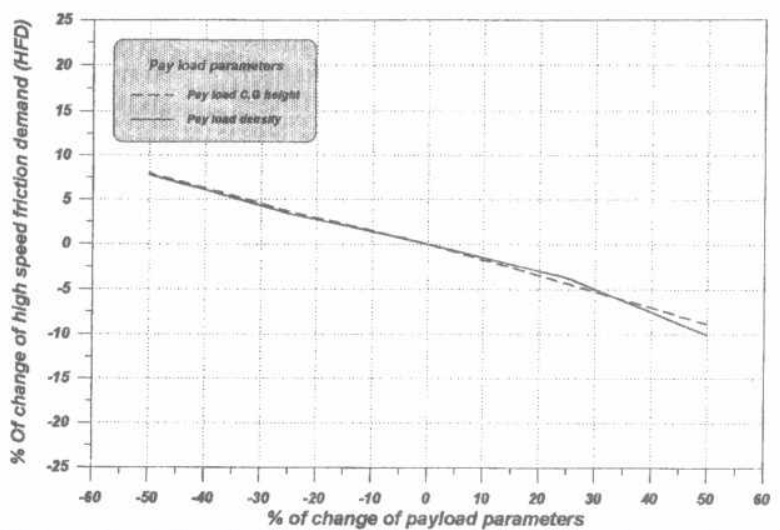

Fig. (13) Influence of payload on HFD during rapid steering lane change maneuver

\section{(5) Offtracking performance}

\section{A. Low speed transient and steady state offtracking}

The influence of payload parameters on low speed transient and steady-state offtracking is shown in Fig. (14).

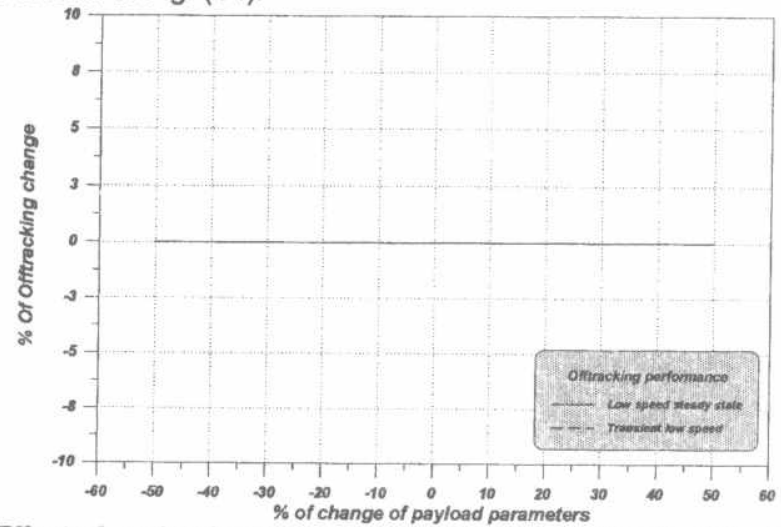

Fig. (14) Effect of payload on low speed transient and Steady state Offtracking. 
There is no any effect of the payload weight change (either this change in the payload density or in the payload C.G. height).

\section{B. High speed-steady-state offtracking}

The influence of payload parameters on high-speed steady-state offtracking is shown in Fig. (15). The calculations are made during two maneuvers, one at radius of 1590 $\mathrm{ft}(484.632 \mathrm{~m})$ and speed $100 \mathrm{~km} / \mathrm{hr}$, and the other at radius of $1045 \mathrm{ft}(318.5 \mathrm{~m})$ and speed of $90 \mathrm{~km} / \mathrm{hr}$. Generally as the payload weight increases high-speed steady offtracking increases also. Increasing payload weight from $-50 \%(9208 \mathrm{Kg})$ to $+50 \%$ $(27624 \mathrm{Kg})$ around the baseline value $(18416 \mathrm{Kg})$ causes an increase of the high speed offtracking from $-68 \%(-0.0697 \mathrm{~m})$ to $+68 \%(-0.36567 \mathrm{~m})$ around the baseline value $(-0.21766 \mathrm{~m}$ ) in case of (maneuver of radius of $1590 \mathrm{ft}$ and speed $100 \mathrm{~km} / \mathrm{h}$ ), and from $-58 \%(-0.07157 \mathrm{~m})$ to $+58 \%(-0.26925 \mathrm{~m})$ around the baseline value ($0.17041 \mathrm{~m}$ ) in case of (maneuver of radius of $1045 \mathrm{ft}$ and speed $90 \mathrm{~km} / \mathrm{h}$ ). There is no difference between the change by payload density or by payload C.G. height).

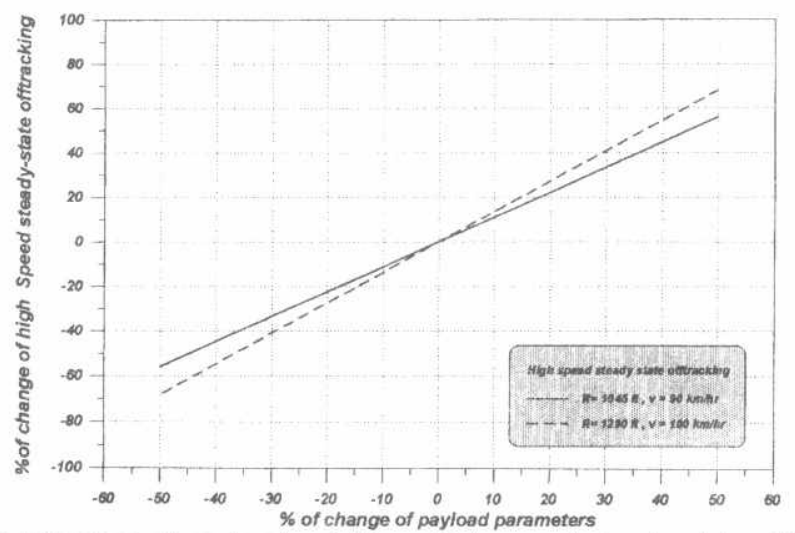

Fig. (15) Influence of payload weight on high-speed steady-state offtracking

\section{(6) Handling characteristics}

The evaluation of the handling characteristics of the tractor-semitrailer based on the three-point diagram, through which the controliability and stability of a given combination can be determined. The figures 16 and 17 show the effect of different payload parameters on the handling characteristics during ramp step steering maneuver at $100 \mathrm{~km} / \mathrm{hr}$. The effect on each characteristics point $(A, B, C)$ can be explained as follows:

\section{Point (A): (Transition point from understeer to oversteer)}

Figure18 shows the effect of changing of payload on the characteristic point (A). From the figure it is clear that the lateral acceleration at which transition point from understeer to oversteer decreases as the payload weight increases. When the payload weight increases from $-50 \%$ to $+50 \%$, it causes a reduction of $100.7 \%$ in 
case of change by density, and $104.7 \%$ in case of change by C.G. height. There is no significant difference between the change by density or by C.G. height.

\section{Point (B): (Understeer coefficient at lateral acceleration $0.3 \mathrm{~g}$ )}

Figure 19 shows the effect of changing of payload on the characteristic point (B). From the figure it is clear that, as the payload weight increases from $-50 \%$ to $+50 \%$, it will cause a reduction in the understeer coefficient at lateral acceleration $0.3 \mathrm{~g}$ by $450 \%$ in case of change by density, and $-573 \%$ in case of change by C.G. height, which causes a reduction in the stability of the vehicle. But this is limited by the critical understeer coefficient, which must be checked.

There is no significant difference between the change by density or by C.G. height in the region from $-50 \%$ to $0.0 \%$, but for the range from $0.0 \%$ to $+50 \%$, effect of C.G. height produces a difference by $135 \%$ which causes more reduction on the stability.

\section{Point (C): (Understeer coefficient at lateral acceleration $0.15 \mathrm{~g}$ )}

Figure 20 shows the effect of changing of payload on the characteristic point (C). From the figure it is clear that that, as the payload weight increases from $-50 \%$ to $+50 \%$, it causes a reduction in the understeer coefficient at lateral acceleration $0.15 \mathrm{~g}$ by $-61.7 \%$ in case of change by density, and $-96 \%$ in case of change by C.G. height, which causes a reduction on the controllability of the vehicle.

There is no significant difference between the change by weight or by C.G. height in the region from $-50 \%$ to $0.0 \%$, but for the range from $0.0 \%$ to $+50 \%$ effect of C.G. height produces a difference by $34.3 \%$, which causes a reduction in the controllability of the vehicle.

Generally increasing the payload weight will deteriorate the controllability and stability especially for increased C.G. height.

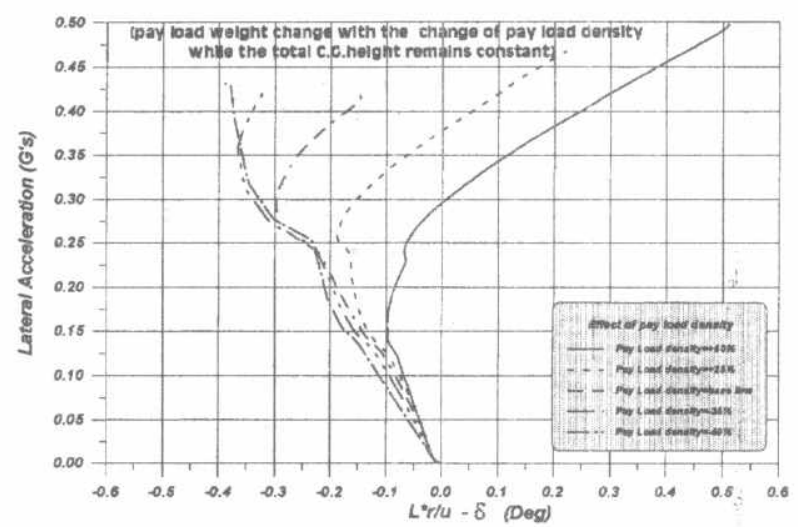

Fig. (16) Influence of payload density on handling performance 


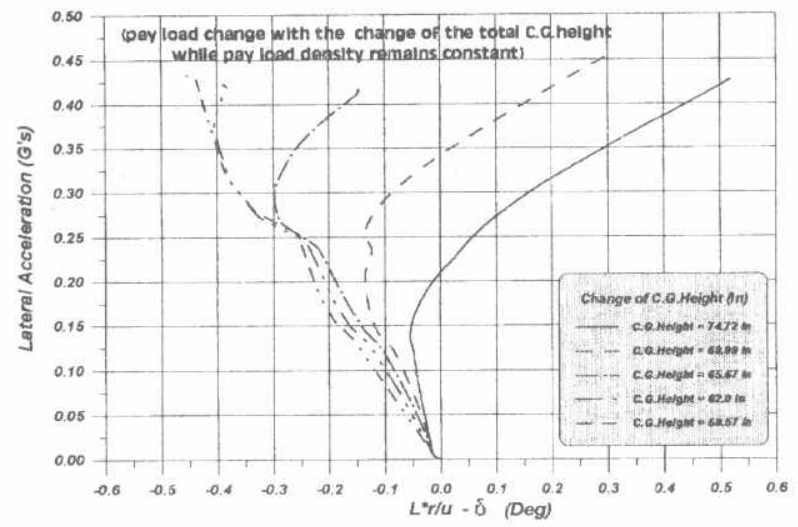

Figure (17) Influence of payload C.G. height on handling performance

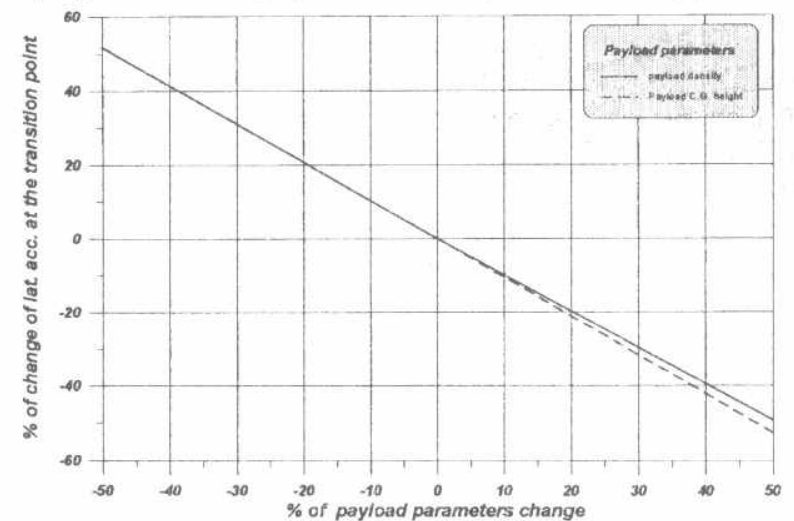

Fig. (18) Application of handling diagram on varied payload (point-A)

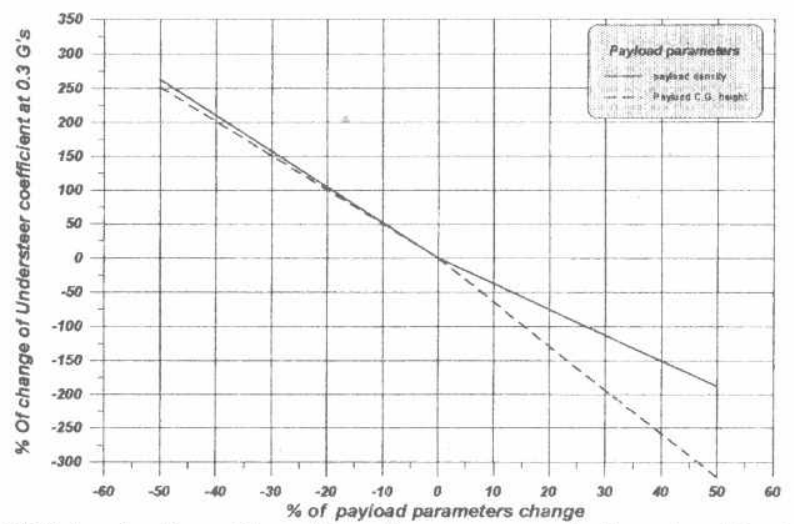

Fig. (19) Application of handling diagram on varied payload (point-B) 


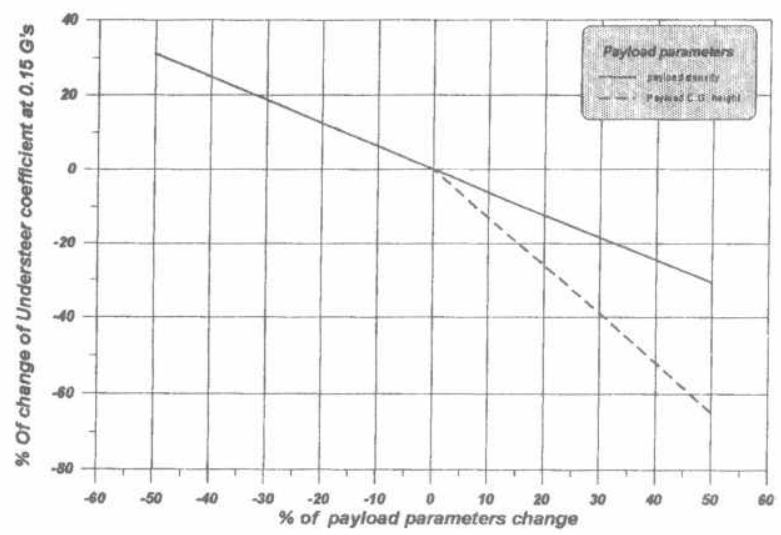

Fig. (20) Application of handling diagram on varied payload (point-C)

\section{CONCL.UDING REMARKS}

From the study reported, the following can be concluded:

One) Increasing the payload weight slightly improves the friction demands properties and nearly has no effect on the offtracking at low speed, while it gives undesirable effect on the offtracking at high speed. Moreover, it deteriorates the controllability and stability of the vehicle.

Two) The study shows that there may exist two loading cases with equal payload weight but with different densities and C.G. heights. In the case of higher C.G., the dynamic rollover stability and yaw stability are reduced. Accordingly regulation laws must limit the C.G. height as with the limitation on axle loads, (i.e. axle load only is not enough limit).

\section{REFERENCES}

[1] Wong, J. Y. and EL-Gindy, M. "Computer Simulation of Heavy Vehicle Dynamic Behavior, User's Guide to the UMTRI Models", Technical Report 3 , Vehicle Weights and Dimensions Study, RTAC, July 1985.

[2] Lin, R. C., Cebon, D., and Cole, D. J. "Validation of an Articulated Vehicle Yaw/Roll Model", University of Cambridge, CUED/C-MECH/TR53, Sept. 1993.

[3] EL-Gindy, M. and Wong, J. Y. "A Comparison of Various Computer Simulation Models For Predicting the Directional Response of Articulated Vehicles", Vehicle System Dynamics, Vol.16, No.5-6, 1989. 
[4] EL-Gindy, M. and Hosamel-deen, Y. H. "Sensitivity Parametric Analysis of UMTRI Static Roll Model", International Journal of Vehicle Design, Vol.10, No. 2, 1989.

[5] EL-Gindy, M. "An Overview of Performance Measures for Heavy Commercial Vehicles in North America", Center for Surface Transportation Technology, National Research Council of Canada, 1995.

[6] EL-Gindy, M. and Preston Thomas, J. "Static Rollover Threshold of Heavy Trucks", Ground Transportation Technology Program, National Research Council Canada, 1992.

[7] El-Gindy, M. "The Use of Heavy Vehicle Performance Measures for Design and Regulation", ASME Winter Meeting, Anaheim, California, November 913,1991 .

[8] Winkler, C. B. and Fancher, P. S. "Scenarios for Regulation of Commercial Vehicle Stability in the US", $4^{\text {th }}$ Int. Heavy Vehicle Seminar Inst. Road Transportation Engineers NZ, Auckland. March 3-5, 1992.

[9] El-Gindy, M. and Woodrooffe, J. H. F. "Influences of Tractor Wheel base, Tandem Axle Spread and Fifth-wheel Offset on Commercial Vehicle Dynamics", Technical Report No. TR-VDL-003, Vehicle Dynamic Laboratory, National Research Council of Canada, Ottawa, 1991.

[10] Winkler, C. B., Karamihas, S. M., and Board, S. E. "Roll Stability Performance of Heavy Vehicle Suspensions", University of Michigan Transportation Research Institute, SAE Paper No. 922426, March 1992.

[11] Winkler, C. B. and Hagan, M. "A Test Facility for The Measurement of Heavy Vehicle suspension Parameters", In current trends in truck suspension. Warrendale, PA. SAE Paper No. 800906. August 1980.

[12] Winkler, C. B. "The Measurement of Inertial Properties and Suspension Parameters of Heavy Highway Vehicles", Paper SAE 730182 presented at SAE International Automotive Engineering Congress, Detroit, January 1973.

[13] Ervin, R. D. "Truck Parameters Measurement", Chapter 21. Mechanics of Heavy Trucks and Truck Combinations. Course notes, Engineering Conference. University of Michigan Transportation Research Institute. An Arbor, Michigan. July 1994.

[14] Fredinad P. Beer and E. Russeil Johnston. "Vector Mechanics for Enginneris Dynamics" Mc Graw - Hill Inc., 1977.

[15] Sharaf, A. M. "Dynamic Performance and Stability of Heavy Articulated Vehicles, M.Sc., Military Technical College, November, 1998. 